\section{Crowdsourcing Bike Share Station Locations: Evaluating participation and placement}

\author{
Greg P. Griffin and Junfeng Jiao
}

Preprint manuscript

The Version of Record of this manuscript is available at (CITE AS):

Griffin, G. P., \& Jiao, J. Crowdsourcing bike share station locations: Evaluating participation and placement. Journal of the American Planning Association. https://doi.org/10.1080/01944363.2018.1476174

\begin{abstract}
Problem, Research Strategy, and Findings: Planners increasingly involve stakeholders in co-producing vital planning information by crowdsourcing data using online map-based commenting platforms. Few studies, however, investigate the role and impact of such online platforms on planning outcomes. We evaluate the impact of participant input via a public participation geographic information system, PPGIS, a platform to suggest placement of new bike share stations in New York City and Chicago. We conducted two analyses to evaluate how close planners built new bike share stations to those suggested on PPGIS platforms. Our proximity analysis found that only a small percent of built stations were within $100 \mathrm{ft}(30 \mathrm{~m})$ of suggested stations, but our geospatial analysis showed a substantial clustering of suggested and built stations in both cities, not likely due to random distribution. We find that the PPGIS platforms have great promise for creating genuine co-production of planning knowledge and insights and that system planners did take account of the suggestions offered online. We did not, however, interview planners in either system, and both cities may be atypical as is bike share planning; moreover, multiple factors influence where bike stations can be located so that not all suggested stations could be built.
\end{abstract}

Takeaway for Practice: Planners can use PPGIS and similar platforms to help stakeholders learn by doing and to increase their own local knowledge to improve planning outcomes. Planners should work to develop better online participatory systems and to allow stakeholders to provide more and better data, continuing to evaluate PPGIS efforts in order to improve the transparency and legitimacy of online public involvement processes.

\title{
Keywords
}

bike share; PPGIS; crowdsourcing; co-production

Public participation is a critical element in most formal US planning processes. The American Institute of Certified Planners' Code of Ethics and Professional Conduct specifies that planners must "give people the opportunity to have a meaningful impact on the development of plans and programs that may affect them" (AICP, 2016). Planners now widely include digital participation methods in their practice, intensifying questions about the efficacy and legitimacy of citizen input. We assess evidence on how planners use crowdsourcing as a form of

About the authors: Greg P. Griffin, AICP (gregpgriffin@utexas.edu or g-griffin@tti.tamu.edu) is a Ph.D. candidate at the University of Texas at Austin. Junfeng Jiao (jjiao@austin.utexas.edu) is an assistant professor at the University of Texas at Austin. 
participation by evaluating cases of bike share system planning in New York (NY) and Chicago (IL). We explored the relationship between where people suggested bike stations and where stations were built in these two cities.

New York and Chicago each used a public participation GIS platform (PPGIS) in conjunction with more traditional neighborhood meetings and community workshops to solicit the views of stakeholders on where to locate bike share stations. Participants using the online platforms could specify the precise location of a suggested bike share station and offer a written defense of their suggestions. Our goal was to understand the extent of co-productive behavior; that is the extent to which planners used the suggestions offered by online participants. We asked two research questions: First, did the bike share systems build stations close to where the public suggested? Second, how does the proximity of suggested and built bike share locations vary geographically across the systems? We used two quantitative metrics to address the two questions, a proximity analysis and a geostatistical analysis (Moran's I); they gave different results.

Our initial proximity analysis found that the two city bike share systems only located $5 \%$ and $10 \%$ of built bike share stations within $100 \mathrm{ft}$ (30 $\mathrm{m})$ of the locations suggested online in NYC and Chicago, respectively. In both cities, participants suggested more stations in downtown than in other areas in the larger metropolitan area. The Chicago bike share system was twice as likely to locate built stations within $100 \mathrm{ft}$ of suggested locations near Chicago's core than it was to locate built stations near suggested locations in the outer ring of the system. This simple relationship did not hold in New York.

Our second analysis, a geostatistical tool, gave us a more nuanced understanding of the spatial relationships between suggested and built stations. We found that a higher percent of suggested and built stations were closely clustered spatially: $15 \%$ and $17 \%$ of suggested stations in NYC and Chicago respectively were statistically close to built stations and not randomly distributed. The two systems built stations statistically closer to suggested stations in the core area (NYC: 17\% and Chicago 29\%), and statistically fewer stations in the in the outer areas of the bike share systems (NYC: $3 \%$ and
Chicago 7\%). We conclude, based on the second analysis, that the PPGIS platform, one of several involvement methods, did have a meaningful impact on where systems located bike share stations, and this constituted a form of coproductive behavior. We admit that there are currently no hard guidelines on how much or how many suggestions planners must listen to or accept for us to be able to confidently say that PPGIS (or any) participants were actively involved in co-productive behavior. Our analyses are based only on quantitative measures as well; we did not interview any of the stakeholders involved although we did read multiple public documents.

We believe our findings have three lessons for planners. First, PPGIS does provide an actionoriented, co-productive approach to collect geographically-specific local ideas for urban planning. Second, PPGIS platforms can support participant learning-by-doing, and provide useful results for planning, if done correctly and if planners know how to use the input effectively. Third, and most significantly, planners and researchers must continue to evaluate PPGIS efforts to improve the transparency and legitimacy of online public involvement processes.

We first discuss the foundations of participatory planning and the role of new technologies in these processes in the following sections; we then provide background on the use of PPGIS in New York City and Chicago, our methods, and results. We conclude by justifying our findings and what we consider their implications for planning, as we just described them here.

\section{Planning with the crowd}

Participatory planning opens a decision-making process to the people likely to be impacted by the ultimate decisions. Urban planning in democratic countries has supported participatory processes since the late $20^{\text {th }}$ Century, valuing input from citizens and explicitly using their ideas in decision-making, albeit at varying levels (Alexander, 2001; Healey, 1997; Margerum, 2002). Planning without a meaningful participatory element runs contrary to traditional tenets of representative democracy, including leadership that respects and understands public views, or at least those of voters (Campbell \& 
Marshall, 2000). Public participation is at the core of current planning practice and is often mandated in formal planning processes by various levels of government (Brody, Godschalk, \& Burby, 2003; Sciara, 2017). Empirical studies demonstrate that the breadth and depth of public involvement contribute to plan strength and implementation (Burby, 2003). Many scholars and participants, however, question the validity and legitimacy of a range of participatory processes (Forester, 2001; Trapenberg Frick, 2013), increasingly including online platforms (Afzalan \& Muller, 2018).

A public process requires broad representation, which may be facilitated by, or even require the use of multiple involvement methods including online based technologies that incorporate social media (Evans-Cowley \& Griffin, 2012; Schweitzer, 2014). Online technologies may allow and even encourage coproductive planning, a concept which involves participants by emphasizing doing planning versus talking about planning, spotlighting specific actions those stakeholders may undertake in concert with government organizations. Coproductive actions are those in which the public performs needed planning roles otherwise conducted by planners within an agency (Watson, 2014). Planners are expanding their use of online participatory technologies to facilitate coproductive planning, in particular, to incorporate crowdsourcing approaches. In crowdsourcing, an organization, like a planning agency, requests information and ideas from a large and relatively open group of Internet users. Participants use an online portal in each instance, through a computer or smartphone, to provide needed information, ideas, or value judgments in response to these direct requests by planners.

Planners have used crowdsourcing techniques to identify and assess historic structures (Minner, Holleran, Roberts, \& Conrad, 2015); collect travel data (Griffin \& Jiao 2015), and to assess property conditions (Thompson, 2016). Some scholars suggest that these techniques might support planning in a manner that is convenient to participants and geographically specific, providing useful information to planners (Evans-Cowley \& Hollander, 2010; Griffin, 2014; Kahila-Tani, Broberg, Kyttä, \& Tyger, 2016). Afzalan and Muller (2018), however, note concerns about how well planners can use some or all data provided online. Planners' increasing use of complex systems and widespread public adoption of information and communication technology opens a knowledge gap on how planners should balance sophistication and openness in participatory planning (Goodspeed, 2016).

Co-production in bike share planning, the focus of this paper, allows and encourages the public to share perceptions and opinions and submit ideas for station locations based on their own experience of the environment. Those community insights could then result in a valuable GIS dataset that planners could integrate with other sources to choose the best locations for bike stations. We take advantage of the speed and relative simplicity of planning for bike share systems to evaluate the actual outcome of online participatory technologies, overcoming challenges that face other evaluation studies. The majority of studies evaluating participation in planning focus on assessing the plan before actual implementation takes place (ex-ante), or during implementation, termed ongoing by Guyadeen and Seasons (2018). Time lag and situational complexity often prevent many planning evaluation studies from connecting process with completed real-world outcomes through ex-post evaluations - a significant gap in knowledge about the effectiveness of planning (Guyadeen and Seasons 2018). Bike sharing, however, is implemented quickly relative to other transportation improvements, allowing ex-post evaluation of the role of the participatory processes that supported those efforts with a minimum of intervening complexities.

We note that the literature suggests that technology-supported public involvement, however useful, may be insufficient to open the planning process to all relevant stakeholders (Desouza \& Bhagwatwar, 2014). Afzalan and Muller (2018) review the literature on the strengths and weaknesses of a variety of online participatory techniques, finding that any online participatory tool inherently excludes those without technology access, knowledge, or interest. Participants, moreover, may be limited in the kind of information they can provide on various platforms, while planners may have challenges evaluating and analyzing the results. Afzalan and Muller (2018) find that planning agencies are often poorly equipped to make the 
best decisions about which technology to acquire and the staffing and training needed to operate these platforms successfully, protect user privacy, and appropriately use the data.

\section{Evaluating the role of PPGIS in Planning for Bike Sharing}

Online public technologies create new opportunities for reaching audiences and stakeholders for participatory planning but create new challenges for planners and publics as well (Afzalan \& Muller, 2018). Civic-oriented software developers have launched replicable PPGIS platforms for collecting geographicallybased public input on a variety of topics. Use of PPGIS and bike sharing technologies are increasingly common, and have stabilized, changing less than during early implementations. However, little plan evaluation research evaluates or measures the impact of PPGIS on actual planning outcomes or impacts.

Most current studies of PPGIS tend to evaluate the tools and methods, that is, ex-ante or ongoing assessments, rather than the outcomes of the participatory process (Brown \& Kyttä, 2014). Planning agencies using PPGIS seldom have the time and resources to perform systematic evaluations of the relationship between public inputs and the results of the planning efforts they are supporting (Guyadeen \& Seasons, 2018; Afzalan \& Muller, 2018). Academics have avoided evaluating the outcomes of PPGIS processes because of the time delay involved in seeing projects come to fruition (Brown \& Kyttä, 2014). A 2016 case study of four United States bike share PPGIS platforms analyzed the potential for representative bias among platform users (Piatkowski, Marshall, \& Afzalan, 2017). The researchers found that the PPGIS contributions did not represent the community at large, concluding that using only the online platform could exacerbate problems for equity of access to the bike share system (Piatkowski, Marshall, \& Afzalan, 2017). Another study of PPGIS use in planning for Muncie (IN) also found bias in geographic representation (Radil \& Jiao, 2016). Bike share planning in Cincinnati $(\mathrm{OH})$ relied on the PPGIS for public input, while

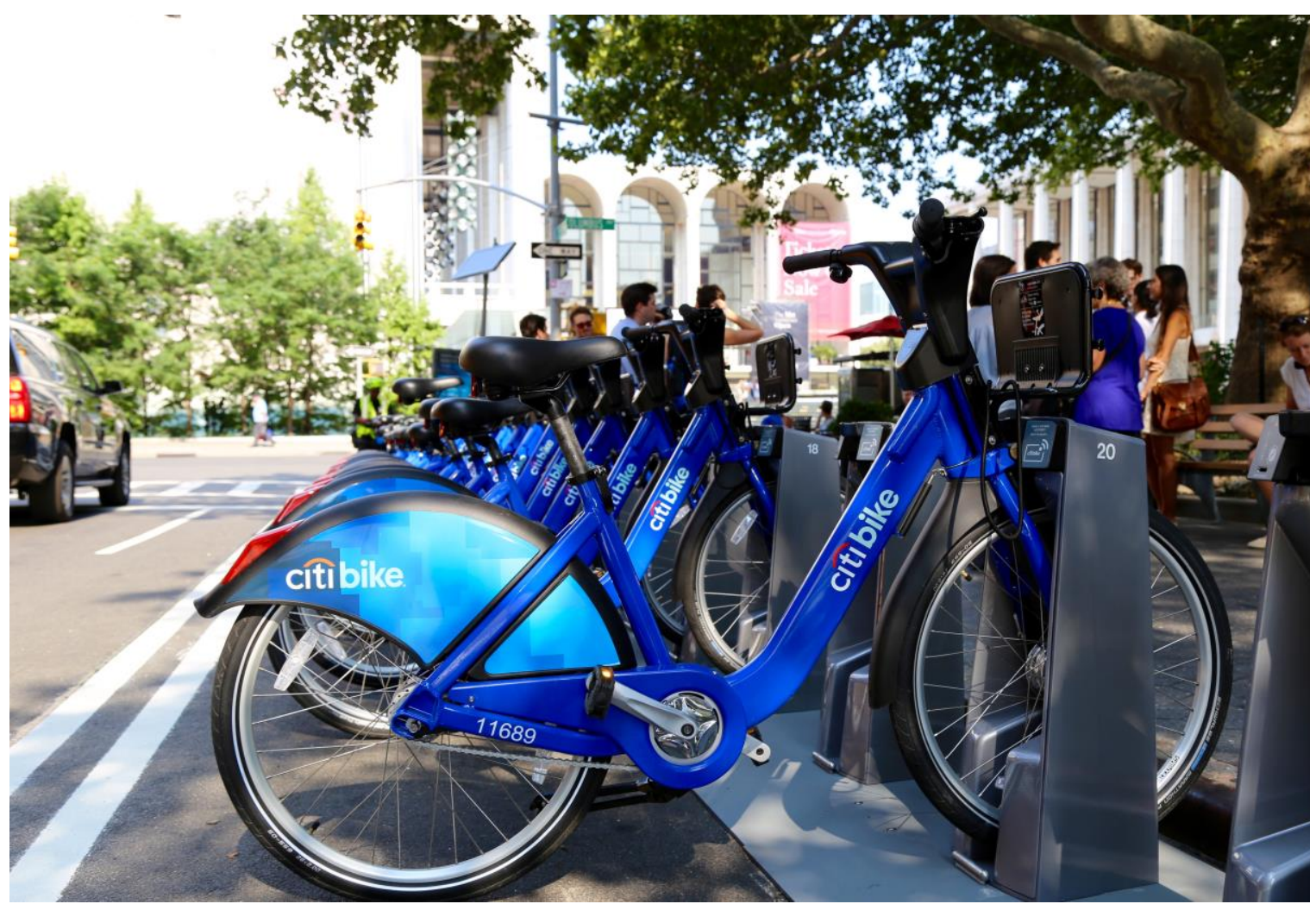

Figure 1. Bike share station in upper Manhattan, New York City. Photo by New York City Department of Transportation (CC BY-NC-ND 2.0) 
holding in-person meetings only with business owners and similar stakeholders (Afzalan \& Sanchez, 2017). The researchers found that planners' lack of time, skills, and funding restricted the use of public comments, suggesting qualitative content analysis skills may "help planners analyze the comments more quickly and easily" (p. 42). Afzalan \& Sanchez (2017) interviewed two planners who said that the ability to combine suggested bike share locations with other GIS data was useful but that they did not use the written comments offered by participants on PPGIS platforms. Brown and Kyttä's 2014 review of fifteen years of PPGIS research argues that "rigorous evaluation of PPGIS outcomes, in contrast with PPGIS tools, is arguably one of the most critically important research needs" ( $p$. 134). Their conclusions, applied to bike share planning, specifically suggest a crucial outcome would be the actual location of constructed bike share stations - the focus of our present study.

\section{Bike Sharing in New York and Chicago}

Bike sharing systems provide access to bicycles in cities, either for rent or at no cost to users. The number of public bike sharing systems has increased quickly in recent years, from only 13 cities across the globe in 2004, to 855 city systems globally a decade later (Fishman, 2016). New York and Chicago's bike sharing systems in 2016 and 2017 use permanent docking stations, where users can check bikes in and out using credit cards or member cards. Figure 1 shows a bike station in the Citi Bike system in New York City.

Bike share systems offer benefits to individuals and communities, varying with context, including traffic conditions, urban densities, and transit service. Short trips taken via bike share are comparable in speed to taxis in New York during rush hour (Faghih-Imani et al., 2017). Bike share ridership is linked to residential and employment density and proximity to rail stations in New York (Noland, Smart, \& Guo, 2016) as well as to how extensive the service area is (Ahillen, Mateo-Babiano, \& Corcoran, 2016). New York and Chicago both have robust systems by these measures, supporting bike share as a complete transportation mode and part of a multimodal system.

New York and Chicago developed and expanded their bike share providing us with critical cases to evaluate the impact of the use of PPGIS on planning outcomes. New York's Citi Bike and Chicago's Divvy bike share program are the first and third largest systems in the United States, based on the number of bikes available (second is the Capital Bikeshare in Washington, D.C.) (O'Brien, 2018). Citi Bike launched in late May 2013 with 6,000 bikes and 332 stations in Manhattan south of $59^{\text {th }}$ street and in Brooklyn north of Atlantic Avenue and west of Nostrand Avenue (Citi Bike, 2016). Divvy launched in June 2013 with 750 bicycles and 75 stations in an area from the Loop north to Berwyn Ave, west to Kedzie Ave, and south to $59^{\text {th }}$ street, rapidly growing to 4,000 bicycles by 2014 (Hilkevitch, 2013; Faghih-Imani \& Eluru, 2015). By the end of 2015, Citi Bike served nearly 45 square miles of New York and into New Jersey, and Divvy covered 145 square miles of the Chicago region. Primary startup funds for Citi Bike came from private sponsorship - including its namesake bank. Divvy's initial rollout, conversely, was supported by government grants, including $\$ 18$ million in federal Congestion Mitigation and Air Quality Improvement Program funds and \$3 million in municipal funds (Cohen and Shaheen, 2016). The source of financing is important because private funding may influence station location, while public funds may be needed to support equity (Howland, et al. 2017). The systems support operations and maintenance through a mix of user fees, private sponsorship, and other sources.

Both systems expanded significantly in 2016. Divvy grew into the communities of Oak Park and Evanston, west and north of Chicago, and Citi Bike into Jersey City, the Upper East Side \& Upper West Side in Manhattan, while adding new stations in Brooklyn (Citi Bike, 2016b; Motivate International \& Divvy Bikes, 2016). By September 2017, Divvy had 5,800 bikes in its system with 580 stations in Chicago, Oak Park, and Evanston. Citi Bike had 10,000 bikes and 706 stations in New York and Jersey City. Citi Bike stations are 976 feet (297 m) apart, on average, and Divvy stations are only slightly wider-spaced, at 1,020 feet $(311 \mathrm{~m})$ average between stations (by our calculations), similar to systems in Montreal and Paris (GarcíaPalomares, Gutiérrez, \& Latorre, 2012).

Both cities have dense populations, mixed land uses, and an extensive system of highly 
connected streets - factors considered supportive of bike share use and bicycling in general (O'Brien, Cheshire, \& Batty, 2014; Pucher \& Buehler, 2012). Chicago is a city of over 2.7 million residents, less than a third that of New York City which had 8.6 million people in 2015 (U.S. Census Bureau Population Division, 2016). Chicago leads the nation in the extent of its protected bike lanes, however, with 161 linear miles, as compared with New York City's 51 miles of protected bike lanes (Alliance for Bicycling and Walking, 2016). Bike lanes protected by buffer space, flexible posts, parked cars, or other traffic devices, may increase both real and perceived safety for bicycling (Lusk et al., 2011; Thomas \& DeRobertis, 2013), making cycling attractive to a broader spectrum of the population, including women (Dill, Goddard, Monsere, \& McNeil, 2015). Roughly $1.4 \%$ of Chicago commuters bicycle to work, versus 1.0\% in New York; these data, however, only count cycling as a commute mode when it is the primary mode to work (and not, for example bicycling to and from transit stops) (Alliance for Bicycling and Walking, 2016; Whitfield, Paul, \& Wendel, 2015). The provision of bicycle infrastructure, bike lanes, and bike sharing systems, consumes street space and funding, requiring planners to consider both the social and physical construction of these systems (Vreugdenhil \& Williams, 2013; Zavestoski \& Agyeman, 2015). These issues, and debates over them, are most visible during public involvement processes.

Formal planning efforts for both Citi Bike and Divvy included in-person public meetings, websites with an interactive PPGIS platform allowing users to suggest bike share station locations, and GIS analysis by planners on optimal bike share station locations. In the initial bike share system planning, New York City DOT conducted in-person workshops with paper maps; planners then combined the locations suggested on paper maps at in-person meetings with the PPGIS results, noting "stations that received votes via the Website [the PPGIS platform] were prioritized over stations that had not" (New York City DOT, 2013, p. 18). The NYC planners vetted stations using technical guidelines on visibility and access, considering sidewalks, on-street sites, parks and other public property, and private property when allowed by owners. DOT planners also developed a GIS model to predict bike share station demand using land use, population density, tourism rates and subway turnstile counts; they then added public input to recommend a location for each 1,000 square foot grid square covering the planning area. NYC DOT planners used published practical guidelines on locating bike share stations (NACTO 2015), "work[ing] to meet the basic rules of station spacing, making sure that stations would be placed approximate 1,000 feet [305 m] apart - a 3-5-minute walk" (New York City DOT, 2013, p. 19) before finalizing bike share station locations . Planners then asked local community board meetings to comment on their draft suggested locations; they also solicited input by posting the locations on the department website. "In total, $43 \%$ of the stations proposed in the draft plans were moved due to community request" (New York City DOT, 2013, p. 19). Documentation of the planning process included some information about the technical methods used by planners such as GIS analysis and station spacing, but emphasized the role of public collaborationsuggesting planners would use public input in siting stations.

Chicago's Divvy planners did not publish a comprehensive process report explaining their planning process and the role of online public input on station locations. The NYC Citi Bike report, however, claims that Chicago and other cities "...have largely replicated the [NYC DOT] approach" (New York City DOT, 2013, p. 19). On April 15, 2015, Chicago Mayor Rahm Emanuel announced that the Divvy systems would expand by 176 stations by June, 2015 to outer areas and would add more stations downtown creating a denser downtown network. The Mayor said: "We are encouraged by Divvy's popularity, and this expansion will ensure more residents in more neighborhoods can access this system," also noting the inclusive process using local suggestions for where stations would be located (Claffey, 2015). A cooperative agreement between the Illinois Department of Transportation, Chicago, and neighboring cities Evanston and Oak Park led to further Divvy expansion when 70 additional stations were built in 2016 (Hurley, 2014). Divvy described the expansion process into Evanston on the north side of Chicago as based on "...data from a survey during the City's Bike Plan Update, a Northwestern University Industrial Engineering 
capstone project, a community meeting, an online survey [the PPGIS], and paper surveys provided at the Levy Senior Center and Evanston Public Library's Main Library" (Divvy, 2015). The Chicago bike share planning process changed slightly between its initial rollout in Chicago and into surrounding cities, but consistently included in-person meetings, PPGIS input, technical analysis, and a final public review.

Respondents on the PPGIS platforms in both cities often provided additional comments or descriptions of the sites they suggested. None of the documents that we reviewed in either city, however, mentioned if or how planners had used those written public comments in their decisionmaking. We do not know, therefore, if bike share system planners did not find these additional comments to be useful or if they lacked the resources to analyze them systematically.

We focus on the impact of the information provided on the two PPGIS platforms, map-based web portals, on the bike share planning process in both city systems. The PPGIS programs in both New York and Chicago were built with an openaccess software platform that combined a map of the city that indicated existing bike share station locations, a map of additional stations already suggested by other participants, and a large "Suggest a Location" button that allowed participants to identify a new station site not already suggested (OpenPlans, 2013). The New York Citi Bike online system prompted participants to provide a written defense of a selected or suggested location in a two-line text box: "this would be a great location because..." Divvy had a similar prompt which asked for a simple "description" of the suggested station (Divvy, 2018). The platforms also incorporated the ability for users to 'like' and comment on others' suggestions; the platform used social media links to spur interest from others online. Neither Chicago nor New York City solicited information on participant demographics, so we cannot directly analyze how representative participants were by income, race, ethnicity, or gender identity.

\section{Are Stations Built in Proximity to Suggested Stations?}

Few studies that evaluate PPGIS platforms used in planning actually measure the outcome or impact on planning decision of the input provided on those platforms. Scholars and practitioners seem to lack practical methods to do so. We also lack comparative metrics on what degree of agreement between crowdsourced participant suggestions and actual planning decisions, or impacts on the ground, constitutes co-productive activity. Participant inputs might conflict, and planners must also consider a range of practical considerations which participants do not consider important or do not rank in the same way. Thus $100 \%$ agreement is neither likely nor beneficial; no relationship between participant suggestions and planning impacts or outcomes, however, is not public participation at all. We have no good scholarship on where to draw the line between the two extremes on this spectrum.

We approach the problem of measuring the impact of crowdsourced suggestions supplied on the PPGIS platform on the planning process for bike share station location using two methods after an initial data collection and refinement stage. We initially obtained and refined the PPGIS data provided in each city in a specific time period. We then conducted two quantitative analyses; we first calculated descriptive statistics such as the average proximity of stations suggested on the PPGIS platforms to built stations overall and then by specific zones in each city. Second, we used a geostatistic analysis that identifies the statistical significance of the proximity of suggested to built stations by identifying clusters of both types of stations that are not likely to occur randomly, again by specific zones in each city. We then set reasonable but arbitrary measures to determine if we could see evidence of co-production, that is, if the input provided by public stakeholders was valued and used by bike share system planners. We decided that there was co-production through crowdsourcing if there was more than $15 \%$ agreement between suggested and built stations in the service area overall or in particular zones in the city, as we defined them.

\section{Evaluating the Input Provided on PPGIS Platforms in New York and Chicago}

Both Citi Bike and Divvy used the Shareabouts platform created and shared by Open Plans (OpenPlans, 2013) to allow stakeholders to suggest and justify new public bike sharing 
stations in New York and Chicago. We accessed the PPGIS databases through the Shareabouts application programming interface (Hebbert, 2016). We downloaded the suggested locations from the date each platform was set up-Citi Bike, October 28, 2014, and Divvy, February 11, 2015-and ending when we web-scraped the PPGIS site information on March 26, 2016. We excluded suggestions after December 31, 2015, providing at least eight months for suggestions to potentially influence station placement before our collection of constructed bike share station locations as they existed on August 3, 2016. This process resulted in a total of 4,744 locations suggested for Citi Bike, and 5,318 for Divvy. Each system implemented multiple waves of expansions and minor relocations over our data collection period. The location of bike share stations are relatively permanent, but cities may relocate stations to alternative locations on a temporary or longer-term basis, due to financial constraints, construction projects near a station (Citi Bike, 2015; Divvy, 2015), and even legal threats (Briquelet, 2013).

We excluded suggested bike share locations outside the service area of the system since neither bike share program imposed any spatial limits on public input; that is, the PPGIS did not automatically require suggestions within a realistic boundary. Fifty-seven percent of the suggested locations for Citi Bike and 15\% of Divvy's were outside of the service boundary as a result. We ended with 2,022 suggested locations in the New York's Citi Bike Share system, and 4,507 in Chicago's Divvy system after excluding suggestions outside the service area.

We were concerned that a few individual participants might suggest a large number of stations or use automated programs to re-enter the same suggestions multiple times, skewing our results. We were able to determine that $93 \%$ of the individual participants on the Citi Bike PPGIS platform suggested only one or two locations (although one user suggested 29 stations). We individually reviewed entries from the top five contributors by the number of locations they suggested, and found they included reasonable locations and descriptions. Therefore, we did not exclude any locations suggested by frequent contributors. We did not have a way to assess the extent to which one or a few users entered multiple sites or multiple times in the Divvy system but since they both used the same OpenPlans platform, the potential for misuse was similar.

Roughly $92 \%$ the locations suggested in Chicago, and $89 \%$ in New York included written comments; respondents in both systems were more likely to include written comments or descriptions of suggested bike share stations sites in the outer parts of the system. In Chicago, for example, respondents provided written comments or descriptions of all $(100 \%)$ of the stations that they suggested in outer areas of the system but only with $88 \%$ of suggested stations in the inner core. We surmise that participants suggesting stations in outlying areas might have felt a greater need to provide planners with local information, details they may have felt that system planners would not know or understand.

We next defined three zones, each system's core, mid-range, and outer areas, to analyze how the proximity of suggested and built locations differed over the metropolitan area as each system expanded. In New York City, we defined the core as Manhattan, the mid-range zone to include Brooklyn and Queens, and the third zone in New Jersey. In Chicago, we measured the distance from the station in the geographic center of the system to the outmost station- 12.5 miles $(20 \mathrm{~km})$, defining the core as the center to the first four miles, the middle section to eight miles, and the rest to an outer zone. The reason for the two different approaches in creating zones is that Chicago's density decreases relatively smoothly from the core to suburb edges in all directions away from Lake Michigan. Conversely, island and river geography dictates much of New York's density. We created the three evaluation zones for each bike share system to generalize density across the large and complex cities.

\section{How Close are Built to Suggested Bike Share Locations?}

Our first analysis assessed the proximity of suggested bike share station locations to built stations as a straight-line distance in each city; we did not use a road network distance, because people often walk to bike stations directly, traversing parking lots, crossing streets at midblock, and across parkland. We determined that the critical distance for a station location to meet the intent of a participant suggesting a station on the PPGIS platform was 100 feet $(30 \mathrm{~m})$ - a tight 
threshold to approximate where a participant intended to place a station site. We use a 100 -foot criterion because it splits the shortest urban blocks of 200 feet [61 m] (Handy, Butler, \& Paterson, 2003) in half, yet provides minimal space for error of placement by contributors (Brown, 2012). We then calculated the percentage of suggested stations within $100 \mathrm{ft}$ of any built stations, as well as the average distance from the bike share station locations suggested on the PPGIS to the nearest built station for each of the three zones in New York and Chicago.

Our second analysis was designed to investigate whether finding built stations near suggested stations $(<100 \mathrm{ft}$ or $30 \mathrm{~m}$ ) was due to random chance. We used a spatial hot spot analysis method called a Local Moran's I (Anselin, 1995; Esri, 2016) to answer this question. This approach reveals whether the proximity between built stations and suggested stations is spatially statistical significant-at a $95 \%$ confidence level. This method has been used by other researchers to identify clusters of phenomena such as social media use in neighborhoods (Anselin \& Williams, 2016), and changes in bicycle ridership (Boss, Nelson, Winters, \& Ferster, in press). We further broke down each system into three zones based on density, because: a) the denser an area is the more likely a suggested and built station would be close to one another whether planners used PPGIS as crowdsourced data or not, and, thus b) the average proximity of suggested to built stations might not accurately describe any given area or allow us to see important differences by community spatial characteristics. We then used the Moran's I analysis to calculate the percent of suggested stations that were statistically significant in proximity to built stations in each zone, identifying clusters of suggestions close to built stations.

Our work has several limitations. First, neither the NYC nor Chicago bike share system explicitly describes how they weighed PPGIS input overall or against other forms of public input. We did review a number of planning documents in both cities that mentioned the role of the PPGIS platforms but the documents gave no clear indication if or how much planners used PPGIS suggestions in making station siting decisions, either alone or in combination with input from more traditional participatory methods. We did not interview bike share system planners about the process so we do not know if and how they balanced the technical challenges with which they were familiar (land use costs, regulatory issues, infrastructure needs, etc) against locations suggested by any stakeholders, as Afzalan and Sanchez (2017) did in their Cincinnati case study. Second, other factors such as market strength to support operational costs, equity considerations, the influence of corporate sponsorships, and a range of local political factors may influence the location of bike share stations - we could not control for any of these factors. Third, neither dataset included the sociodemographic characteristics of online respondents, so we could not assess whether participation on the PPGIS was more or less representative than more traditional participation methods - a crucial planning concern. Fourth, New York and Chicago are hardly typical; their large populations, extensive transit services, and financial resources make them very different from smaller cities considering bike share programs. Some of the differences in the average distances between suggested and constructed stations in both cities are likely associated with their geographic characteristics-New York's service area is spatially smaller, yet is more densely populated and constrained by waterways. Finally, appropriate locations for bike share stations are limited by the spatial constraints of streetscapes, including the location of utilities, transit stops, vehicle parking, accessibility requirements, and other issues.

We are thus limited in our ability to fully assess the impact of suggestions made on the PPGIS platform on the bike sharing system planning process, the extent of true crowdsourcing, although we do draw some preliminary conclusions. An important next step in addressing this increasingly important planning topic would be to conduct extensive interviews with all relevant stakeholders in PPGIS planning processes to learn how they understood and used citizen input from different sources, and to assess whether those participating online were more or less representative of a broader community of stakeholders than those involved in traditional participatory processes. 


\section{Crowdsourcing and Planning Bike Share in New York and Chicago}

Participants on both the Citi Bike and Divvy PPGIS platforms suggested a total of 10,062 individual bike share locations over the study period, 4,744 in the New York City area and 5,318 around Chicago. Only $85 \%$ of suggested Divvy Bike bike share stations and $43 \%$ of suggested Citi bike share stations were within the boundary of these systems as of 2016. We excluded from our analysis any suggested stations outside of the system boundaries, giving us a total of 6,529 (NY: 2,022 and Chicago: 4,507) suggested bike share locations.

Participants suggested more stations in the core of both cities than in the inner suburbs or outer-edges. Participants also suggested nearly four times more stations in Chicago overall and more than seven times more stations in New York overall than the systems built. The ratio of suggested to built stations differed substantially by area of the city. Divvy participants suggested 8.1, 7.9, and 6.1 times more stations than were built in inner, middle and outer rings, respectively. In New York, the Citi Bike system received 4.4, 3.6, and 1.3 more suggested stations than it built.

Table 1 shows that across the Citi Bike service area, participants suggested 2022 locations, with 523 stations built in the service area. The ratio of locations suggested to built was 3.9 for the Citi Bike system, and nearly twice as high for Divvy: 7.8 locations for each built station. Table 1 also shows the site of suggested bike share stations; over eight were suggested in Chicago's inner ring, but only just over one per station in New Jersey. Moreover, Table 1 shows how many suggested and built bike stations there were in each of the three zones in each city. Nine percent of the Citi Bike stations were built in New Jersey, the third zone, where only $3 \%$ of suggested stations were located. The reverse is true in Manhattan, the inner zone, which included $67 \%$ of suggested Citi Bike stations but received only $59 \%$ of the built stations. There was, however, less difference in the spatial concordance between and among suggested and built stations in Chicago's three zones.

Our analysis of the 100-foot distance criteria between suggested stations and placement by each system suggests PPGIS suggestions' limited influence on bike share implementation. Table 2 shows that only $10 \%$ of suggested stations in Chicago had at least one built station within 100 $\mathrm{ft}(30 \mathrm{~m})$; in New York the comparable figure was only $5 \%$. The distance between suggested and built stations did differ by part of the city, but the differences were not large - but were surprisingly different in the two cities. We saw the pattern we might have expected in Chicago - the spatial concurrence between suggested and built stations was highest in the core and lowest in the outer ring. Twelve percent of suggested stations were within $100 \mathrm{ft}$ of a built station in the core of Chicago, falling to $7 \%$ in the mid-range ring, and

Table 1. Suggested and built stations in each system

\begin{tabular}{|c|c|c|c|c|c|c|}
\hline $\begin{array}{c}\text { Bike Share } \\
\text { System }\end{array}$ & Zones & Suggested & Built & $\begin{array}{l}\text { Suggested/ } \\
\text { Built Ratio P }\end{array}$ & $\begin{array}{l}\text { Suggested } \\
\text { Percentage }\end{array}$ & $\begin{array}{c}\text { Built } \\
\text { Percentage } \\
\end{array}$ \\
\hline \multirow{4}{*}{ Divvy } & Inner Ring & 2515 & 309 & 8.1 & $56 \%$ & $54 \%$ \\
\hline & Middle Ring & 1557 & 197 & 7.9 & $35 \%$ & $34 \%$ \\
\hline & Outer Ring & 435 & 71 & 6.1 & $10 \%$ & $12 \%$ \\
\hline & $\begin{array}{l}\text { All Service } \\
\text { Areas }\end{array}$ & 4507 & 577 & 7.8 & $100 \%$ & $100 \%$ \\
\hline \multirow{4}{*}{ Citi Bike } & Manhattan & 1349 & 308 & 4.4 & $67 \%$ & $59 \%$ \\
\hline & $\begin{array}{l}\text { Brooklyn \& } \\
\text { Queens }\end{array}$ & 612 & 168 & 3.6 & $30 \%$ & $32 \%$ \\
\hline & New Jersey & 61 & 47 & 1.3 & $3 \%$ & $9 \%$ \\
\hline & $\begin{array}{l}\text { All Service } \\
\text { Areas }\end{array}$ & 2022 & 523 & 3.9 & $100 \%$ & $100 \%$ \\
\hline
\end{tabular}


Table 2. Suggested stations within $100 \mathrm{ft}$ to built stations in each system

\begin{tabular}{llrrr}
\hline $\begin{array}{c}\text { Bike Share } \\
\text { System }\end{array}$ & \multicolumn{1}{c}{ Zones } & $\begin{array}{c}\text { Suggested stations } \\
\text { within 100ft of built } \\
\text { stations }\end{array}$ & Percent & Total \\
\hline \multirow{3}{*}{ Divvy } & Inner Ring & 300 & $12 \%$ & 2,515 \\
& Middle Ring & 111 & $7 \%$ & 1,557 \\
& Outer Ring & 24 & $6 \%$ & 435 \\
& All Service Areas & 435 & $10 \%$ & 4,507 \\
\hline \multirow{6}{*}{ Citi Bike } & Manhattan & 47 & $3 \%$ & 1,349 \\
& Brooklyn \& Queens & 57 & $9 \%$ & 612 \\
& New Jersey & 1 & $2 \%$ & 61 \\
& All Service Areas & 105 & $5 \%$ & 2,022 \\
\hline
\end{tabular}

to $6 \%$ in the outer ring.

Conversely, only $3 \%$ of built stations were within $100 \mathrm{ft}(30 \mathrm{~m})$ of a suggested station in the inner ring in New York City, Manhattan. We believe much of the Citibike system was already intensively deployed in the core during our analysis - people were not suggesting stations for areas where service already existed; the most appropriate locations were already served. Nine percent of built stations in New York's Zone 2, Brooklyn and Queens, where there was more opportunity for growth, were within 100 feet of a suggested station. There was even more opportunity to expand service into the large New Jersey ring, but only one station was built within 100 feet of a suggested station in the New Jersey during our study period (fall 2014 to spring 2016). One limitation of setting a single distance criterion is that it may not suit a wide range of urban densities. For instance, people may consider a bike share station placed at a further distance from their suggestion suitable in the suburbs, relative to downtown contexts.

We also conducted a second analysis, using a spatial statistical method; the Local Moran's I (Anselin, 1995, Esri, 2016), to investigate the relationship between suggested stations and built stations in each city. In contrast to the static 100 $\mathrm{ft}(30 \mathrm{~m})$ criterion, this method identifies clusters using a relative measure, as "groups of locations that have more similar values to their neighbors than would be expected under spatial randomness" (Anselin \& Williams, 2016). We used a straight-line distance between a suggested station and the nearest built bike share station as the weighting factor in the Local Moran's I calculation, resulting in spatial groupings of suggested locations where the distance to a built station were similar in proximity, at least a $95 \%$ confidence interval. We chose an inverse distance conceptualization of spatial relationships in the Local Moran's I calculation, resulting in relative clusters of nearness, where nearby PPGIS suggestions have a more substantial influence than those that are further away (Esri, 2016). We chose not to use other spatial conceptualizations that impose distance limits or sharp edges, to emphasize relative nearness, differentiating the clustering approach from the simple distance criterion. This relative, rather than absolute, approach to distance and clustering helps deal with the wide variance in densities across the large regions, providing a metric that is specific to each bike share system's context.

This analysis found that there was more spatial relationship between suggested and built stations in both systems than our first analysis indicated. Table 3 shows that $17 \%$ and $15 \%$ of suggested stations were clustered spatially, that is statistically close to actually built stations in Chicago and New York using the Local Moran's I measure. In Chicago, 29\% of suggested stations in the inner ring were statistically close to built stations. Conversely, only $2 \%$ and $7 \%$ of suggested stations were statistically close to built stations in the middle and outer rings of Chicago. Analysis of spatial clusters of suggestions' proximity to built stations identifies areas that 
were relatively well-served (or not), sensitive to relative densities throughout each system.

Seventeen percent of the suggested stations in New York's inner zone, Manhattan, were statistically close to built bike sharing stations. Twelve percent of suggested stations in Zone 2, Brooklyn and Queens, were statistically close to built stations, but only $2 \%$ of suggested stations were statistically close to built stations in Zone 3, Jersey City.

There are no accepted numerical measures to determine the point at which we can say that crowdsourced data constitutes coproduction, that planners have sufficiently listened to or accepted suggestions from participants in online platforms (or from conventional participatory fora-public hearings or focus groups - for that matter). The lack of research on the impact of participatory processes means we have little previous work to build on or to which to compare our findings. We feel, however, that if $15 \%$ of suggested stations are within $100 \mathrm{ft}$ of built bike share station in the system overall or in specific parts of the system, then the input provided by participants on the PPGIS does constitute genuine co-production through crowdsourcing.

Our second analysis, focusing on spatial clustering of suggested and built stations, shows that both cities met that standard for the system as a whole, although not in the most distant and generally least dense zones. There are, however, so many opportunities for bike share stations in more distant areas, and limited ability to provide stations in all those sites, that not meeting the $15 \%$ standard in those areas does not show that planners were not considering crowdsourced input, but perhaps only that the resources available were not sufficient to build all the suggested stations.

\section{Crowdsourcing as Co-productive Public Engagement}

Our study first asked whether bike share systems in New York and Chicago built stations close to where participants suggested on public participation GIS platforms; and second, did the proximity and spatial relationship between suggested and built bike share locations vary geographically across the two systems? Our goal was to link geographically specific public input to the actual outcomes of bike share station planning. We did so using two types of analyses: first a proximity analysis that determined the straight-line distances between suggested and built bike stations focusing on stations built within $100 \mathrm{ft}(33 \mathrm{~m})$ of suggested stations; and, second, the Local Moran's $I$, which determines if there are clusters of suggested and built bike stations that did not occur randomly. We computed these measures for both city systems and then for three zones within each city.

Our initial analyses did not find many built bike share stations within $100 \mathrm{ft}(33 \mathrm{~m})$ of suggested stations in either city; we offer $100 \mathrm{ft}$ as a reasonable distance to differentiate placement of a bike share station within urban

Table 3. Suggested stations statistically close to built stations in each system

\begin{tabular}{llrrr}
$\begin{array}{c}\text { Bike Share } \\
\text { System }\end{array}$ & \multicolumn{1}{c}{ Zones } & $\begin{array}{c}\text { Suggestions } \\
\text { Statistically Close to } \\
\text { Built Stations* }\end{array}$ & Percent & Total \\
\hline \multirow{3}{*}{ Divvy } & Inner Ring & 717 & $29 \%$ & 2,515 \\
& Middle Ring & 33 & $2 \%$ & 1,557 \\
& Outer Ring & 31 & $7 \%$ & 435 \\
& All Service Areas & 781 & $17 \%$ & 4,507 \\
\hline \multirow{6}{*}{ Citi Bike } & Manhattan & 234 & $17 \%$ & 1,349 \\
& Brooklyn \& Queens & 76 & $12 \%$ & 612 \\
& New Jersey & 2 & $3 \%$ & 61 \\
& All Service Areas & 312 & $15 \%$ & 2,022 \\
\hline
\end{tabular}

* Close proximity calculated with Local Moran's / higher than average, with $p=<0.05$ 
blocks. The proximity analysis did not find that more than $10 \%$ of suggested stations were within $100 \mathrm{ft}$ of suggested stations in either the New York or Chicago systems as a whole, although that percentage varied by area of the city. Our second spatial analysis, using Moran's I, however, did find much more statistically significant clustering of suggested and built stations, clusters not randomly generated, and over our $15 \%$ metric indicating that planners used the input provided by participants on the PPGIS platforms in both cities. We conclude then that crowdsourcing can and does impact the decisions taken by bike share station planners, that there was genuine co-production of planning data and analyses. We believe that these two cases indicate that crowdsourcing portions of the planning process - such as identifying candidate locations for bike share stations - is co-productive: people can perform a portion of the planning process, rather than just view and comment on planners' ideas.

Our analysis of the PPGIS platforms in planning bike share stations in New York and Chicago suggests that such participatory mechanisms have great promise for creating genuine co-production of planning knowledge and insights. Participants provided many suggestions and offered insights and local knowledge in their written defense or description of suggested sites. Our analysis indicates, but does not prove, that system planners did consider and incorporate some of the input received through the PPGIS platform. Our second geospatial analysis clearly shows areas where there were many stations built relatively close to suggested stations in a manner not due to a random distribution. Overall, we believe that map-based crowdsourcing is an approach that provides a way for people to do some of the work of planning, instead of just talking about it-a coproductive participation technique.

We could not tell how influential PPGIS results were in the final planning decisions because a) there are only so many feasible bike share station sites in the core of each city, and, b) staff reports gave no in-depth indication of how they weighted the PPGIS results against the input at the more traditional participatory exercises in which they also engaged. Placing bike share stations is a relatively straightforward planning problem so our analysis does not indicate how useful a platform like PPGIS would be in handling far more complex and controversial issues, such as siting public housing or a major transit station, for example.

We believe, however, that PPGIS platforms have the potential to support participants' learning-by-doing, and improve planners' local knowledge in ways that will improve planning outcomes. Planners can better implement PPGIS as a participatory technology by working with technologists to design better systems and to carefully apply their limited budgets on systems appropriate for local contexts. PPGIS designs can allow participants to provide more layers of information than provided in the two cases on which we focused, while providing a functional planning boundary or guidance to avoid unrealistic suggestions.

We also need to improve our understanding of the social processes of planners, elected officials, publics, and how they interact with technological developments in PPGIS and other online crowdsourcing approaches to change how the technologies are understood and valued (Vreugdenhil \& Williams, 2013). This kind of knowledge could inform both design of online participatory systems and how planners deploy them as part of public engagement. These lines of further research support a better understanding of how new technologies and social processes influence public engagement in planning.

\section{References}

Afzalan, N., \& Muller, B. (2018). Online participatory technologies: opportunities and challenges for enriching participatory planning. Journal of the American Planning Association, 84(2), 162-177. doi:10.1080/01944363.2018.1434010

Afzalan, N., \& Sanchez, T. W. (2017). Testing the use of crowdsourced information: Case study of bike-share infrastructure planning in Cincinnati, Ohio. Urban Planning, 2(3), 3344. doi:10.17645/up.v2i3.1013

Ahillen, M., Mateo-Babiano, D., \& Corcoran, J. (2016). The dynamics of bike-sharing in Washington, D.C. and Brisbane, Australia: Implications for policy and planning. International Journal of Sustainable Transportation, 10(5), 441-454. doi:10.1080/15568318.2014.966933

AICP. (2016). Code of Ethics and Professional 
Conduct. Retrieved January 28, 2018, from https://www.planning.org/ethics/ethicscode/

Alexander, E. R. (2001). The planner-prince: interdependence, rationalities and postcommunicative practice. Planning Theory \& Practice, 2(3), 311-324.

doi:10.1080/14649350120096848

Alliance for Bicycling and Walking. (2016). Bicycling and walking in the United States 2016 benchmarking report. Washington, D.C.: Alliance for Bicycling and Walking. Retrieved from http://bikingandwalkingbenchmarks.org/back end/sites/default/files/2016benchmarkingrepo rt web.pdf

Anselin, L. (1995). Local Indicators of Spatial Association-LISA. Geographical Analysis, 27(2), 93-115. doi:10.1111/j.15384632.1995.tb00338.x

Anselin, L., \& Williams, S. (2016). Digital neighborhoods. Journal of Urbanism: International Research on Placemaking and Urban Sustainability, 9(4), 305-328. doi:10.1080/17549175.2015.1080752

Boss, D., Nelson, T., Winters, M., \& Ferster, C. J. (in press). Using crowdsourced data to monitor change in spatial patterns of bicycle ridership. Journal of Transport \& Health . doi:10.1016/j.jth.2018.02.008

Briquelet, K. (2013). City moves Citi Bike stations from richest areas while letting other contested racks stay. Retrieved March 2, 2017, from http://nypost.com/2013/06/23/city-movesciti-bike-stations-from-richest-areas-whileletting-other-contested-racks-stay/

Brody, S. D., Godschalk, D. R., \& Burby, R. J. (2003). Mandating citizen participation in plan making: six strategic planning choices. Journal of the American Planning Association, 69(3), 245-264. doi: $10.1080 / 01944360308978018$

Brown, G. (2012). An empirical evaluation of the spatial accuracy of public participation GIS (PPGIS) data. Applied Geography, 34, 289-294. doi:10.1016/j.apgeog.2011.12.004

Brown, G., \& Kyttä, M. (2014). Key issues and research priorities for public participation GIS (PPGIS): A synthesis based on empirical research. Applied Geography, 46, 122-136. doi:10.1016/j.apgeog.2013.11.004

Burby, R. J. (2003). Making plans that matter:
Citizen involvement and government action. Journal of the American Planning Association, 69(1), 33-49. doi:10.1080/01944360308976292

Campbell, H., \& Marshall, R. (2000). Public involvement and planning: Looking beyond the one to the many. International Planning Studies, 5(3), 321-344. doi:10.1080/713672862

Citi Bike. (2015). Station relocation! Retrieved March 2, 2017, from http://citibikeblog.tumblr.com/post/11196863 7572/station-relocation-we-need-totemporarily-move

Citi Bike. (2016). About Citi Bike: company, history. Retrieved August 14, 2016, from https://www.citibikenyc.com/about

Citi Bike. (2016b). Expansion 2016. Retrieved August 14, 2016, from https://www.citibikenyc.com/expansion

Claffey, M. (2015). Mayor Emanuel announces Divvy expanding to new neighborhoods. Retrieved February 23, 2017, from https://www.cityofchicago.org/city/en/depts/c dot/provdrs/bike/news/2015/april/mayoremanuel-announces-divvy-expanding-tonew-neighborhoods.html

Cohen, A., \& Shaheen, S. (2016). Planning for Shared Mobility (PAS 583). Chicago: IL: American Planning Association. Retrieved from

https://www.planning.org/publications/report/ 9107556/

Desouza, K. C., \& Bhagwatwar, A. (2014). Technology-enabled participatory platforms for civic engagement: the case of U.S. cities. Journal of Urban Technology, 21(4), 25-50. doi:10.1080/10630732.2014.954898

Dill, J., Goddard, T., Monsere, C. M., \& McNeil, N. (2015). Can protected bike lanes help close the gender gap in cycling? Lessons from five cities. Transportation Research Board 94th Annual Meeting. Washington, D.C, January 11-15, 2015. Washington, D.C.: Transportation Research Board of the National Academies.

Divvy. (2015). Station Moves: Union Station Construction Update. Retrieved March 2, 2017, from http://divvybikes.tumblr.com/post/940014384 95/station-moves-union-station-constructionupdate 
Divvy Bikes. (2018). Suggest a Location.

Retrieved February 24, 2018, from http://suggest.divvybikes.com

Esri. (2016). Cluster and outlier analysis (Anselin Local Moran's I). Retrieved August 9, 2016, from

http://desktop.arcgis.com/en/arcmap/10.3/tool s/spatial-statistics-toolbox/cluster-andoutlier-analysis-anselin-local-moran-s.htm

Evans-Cowley, J. S., \& Griffin, G. (2012). Microparticipation with social media for community engagement in transportation planning. Transportation Research Record: Journal of the Transportation Research Board, 2307, 90-98. doi:10.3141/2307-10

Evans-Cowley, J., \& Hollander, J. (2010). The new generation of public participation: internet-based participation tools. Planning Practice and Research, 25(3), 397-408. doi:10.1080/02697459.2010.503432

Faghih-Imani, A., \& Eluru, N. (2015). Analysing destination choice preferences in bicycle sharing systems: an investigation of Chicago's Divvy system. Transportation Research Board 94th Annual Meeting. Washington, D.C, January 11-15, 2015. Washington, D.C.: Transportation Research Board of the National Academies.

Faghih-Imani, A., Anowar, S., Miller, E. J., \& Eluru, N. (2017). Hail a cab or ride a bike? A travel time comparison of taxi and bicyclesharing systems in New York City. Transportation Research Part A: Policy and Practice, 101, 11-21. doi:10.1016/j.tra.2017.05.006

Fishman, E. (2016). Bikeshare: a review of recent literature. Transport Reviews, 36(1), 92-113. doi:10.1080/01441647.2015.1033036

Forester, J. (2001). An instructive case-study hampered by theoretical puzzles: critical comments on Flyvbjerg's Rationality and Power. International Planning Studies, 6(3), 263-270. doi:10.1080/713672905

García-Palomares, J. C., Gutiérrez, J., \& Latorre, M. (2012). Optimizing the location of stations in bike-sharing programs: A GIS approach. Applied Geography, 35, 235-246. doi:10.1016/j.apgeog.2012.07.002

Goodspeed, R. (2016). Digital knowledge technologies in planning practice: from black boxes to media for collaborative inquiry.
Planning Theory \& Practice, 17(4), 577-600. doi:10.1080/14649357.2016.1212996

Griffin, G. P. (2014). Geographic specificity and positionality of public input in transportation: a rural transportation planning case from Central Texas. Urban, Planning and Transport Research, 2(1), 407-422. doi:10.1080/21650020.2014.969442

Griffin, G. P., \& Jiao, J. (2015). Crowdsourcing bicycle volumes: Exploring the role of volunteered geographic information and established monitoring methods. URISA Journal, 27(1), 57-66. Retrieved from https://ssrn.com/abstract $=2668747$

Guyadeen, D., \& Seasons, M. (2018). Evaluation theory and practice: Comparing program evaluation and evaluation in planning. Journal of Planning Education and Research, 38(1), 98-110. doi:10.1177/0739456X16675930

Handy, S. L., Butler, K. S., \& Paterson, R. G. (2003). PAS Report 515 Planning for street connectivity - getting from here to there. Chicago: IL: American Planning Association.

Healey, P. (1997). Collaborative planning: shaping places in fragmented societies. London: Macmillan.

Hebbert, F. (2016). Viewing data via the Django admin interface. Retrieved March 20, 2016, from

https://github.com/openplans/shareaboutsapi/blob/master/doc/GETTING YOUR DAT A.md

Hilkevitch, J. (2013, April 25). Chicago ready to roll out bike-sharing. Chicago Tribune.

Retrieved from

http://www.chicagotribune.com/news/ct-metbike-sharing-divvy-0425-20130425story.html

Howland, S., McNeil, N., Broach, J., Rankins, K., MacArthur, J., \& Dill, J. (2017). Current Efforts to Make Bikeshare More Equitable. Transportation Research Record: Journal of the Transportation Research Board, 2662, 160-167. doi:10.3141/2662-18

Hurley, C. (2014). Divvy Bicycle Share Evanston Expansion. Retrieved May 27, 2016, from http://www.cityofevanston.org/assets/SP3 CityCouncil_DivvyPresentation_Nov17 v2.pdf

Kahila-Tani, M., Broberg, A., Kyttä, M., \& 
Tyger, T. (2016). Let the citizens mappublic participation GIS as a planning support system in the Helsinki master plan process. Planning Practice \& Research, 31(2), 195-214. doi:10.1080/02697459.2015.1104203

Lusk, A. C., Furth, P. G., Morency, P., MirandaMoreno, L. F., Willett, W. C., \& Dennerlein, J. T. (2011). Risk of injury for bicycling on cycle tracks versus in the street. Injury Prevention, 17(2), 131-135. doi:10.1136/ip.2010.028696

Margerum, R. D. (2002). Evaluating collaborative planning: implications from an empirical analysis of growth management. Journal of the American Planning Association, 68(2), 179-193. doi:10.1080/01944360208976264

Minner, J., Holleran, M., Roberts, A., \& Conrad, J. (2015). Capturing volunteered historical information: lessons from development of a local government crowdsourcing tool. International Journal of E-Planning Research, 4(1), 19-41. doi:10.4018/ijepr.2015010102

Motivate International, \& Divvy Bikes. (2016). About Divvy. Retrieved August 14, 2016, from https://www.divvybikes.com/about

NACTO. (2015). Walkable Station Spacing is Key to Successful, Equitable Bike Share. (NACTO Bike Share Equity Practitioners' Paper \#1). New York City: National Association of City Transportation Officials. Retrieved from https://nacto.org/wpcontent/uploads/2015/06/NACTO_WalkableStation-Spacing-Is-Key-For-Bike-Share.pdf

New York City DOT. (2013). NYC bike share designed by New Yorkers. Retrieved May 26, 2016, from www.nyc.gov/html/dot/downloads/pdf/bikeshare-outreach-report.pdf

Noland, R. B., Smart, M. J., \& Guo, Z. (2016). Bikeshare trip generation in New York City. Transportation Research Part A: Policy and Practice, 94, 164-181. doi:10.1016/j.tra.2016.08.030

O'Brien, O. (2018). Bike Share Map. Retrieved January 25, 2018, from http://bikes.oobrien.com/

O'Brien, O., Cheshire, J., \& Batty, M. (2014). Mining bicycle sharing data for generating insights into sustainable transport systems.
Journal of Transport Geography, 34, 262273. doi:10.1016/j.jtrangeo.2013.06.007

OpenPlans. (2013). Shareabouts. Retrieved January 25, 2018, from https://github.com/openplans/shareabouts

Piatkowski, D., Marshall, W., \& Afzalan, N. (2017). Can web-based community engagement inform equitable planning outcomes? A case study of bikesharing. Journal of Urbanism: International Research on Placemaking and Urban Sustainability, 10(3), 296-309. doi:10.1080/17549175.2016.1254672

Pucher, J. R., \& Buehler, R. (2012). City cycling. (J. Pucher \& R. Buehler, Eds.). Cambridge, MA: MIT Press.

Radil, S. M., \& Jiao, J. (2016). Public participatory GIS and the geography of inclusion. The Professional Geographer, 68(2), 202-210. doi:10.1080/00330124.2015.1054750

Schweitzer, L. (2014). Planning and social media: A case study of public transit and stigma on Twitter. Journal of the American Planning Association, 80(3), 218-238. doi:10.1080/01944363.2014.980439

Sciara, G.-C. (2017). Metropolitan transportation planning: lessons from the past, institutions for the future. Journal of the American Planning Association, 83(3), 262276. doi:10.1080/01944363.2017.1322526

Thomas, B., \& DeRobertis, M. (2013). The safety of urban cycle tracks: a review of the literature. Accident Analysis \& Prevention, 52, 219-27. doi:10.1016/j.aap.2012.12.017

Thompson, M. M. (2016). Upside-Down GIS: The Future of Citizen Science and Community Participation. The Cartographic Journal, 53(4), 1-9. doi:10.1080/00087041.2016.1243863

Trapenberg Frick, K. (2013). The actions of discontent: tea party and property rights activists pushing back against regional planning. Journal of the American Planning Association, 79(3), 190-200. doi:10.1080/01944363.2013.885312

U.S. Census Bureau Population Division. (2016). Annual estimates of the resident population: April 1, 2010 to July 1, 2015. Retrieved June 20, 2008, from http://factfinder.census.gov/

Vreugdenhil, R., \& Williams, S. (2013). White 
line fever: A sociotechnical perspective on the contested implementation of an urban bike lane network. Area, 45(3), 283-291. doi:10.1111/area.12029

Watson, V. (2014). Co-production and collaboration in planning - the difference. Planning Theory \& Practice, 15(1), 62-76. doi:10.1080/14649357.2013.866266

Whitfield, G. P., Paul, P., \& Wendel, A. M. (2015). Active transportation surveillance United States, 1999 - 2012. MMWR Surveillance Summaries, 64(7), 1-17.

Zavestoski, S., \& Agyeman, J. (2015). Towards an understanding of complete streets. In S.
Zavestoski \& J. Agyeman (Eds.), Incomplete streets: processes, practices and possibilities (pp. 307-315). Abington: Routledge.

\section{Acknowledgements}

The authors greatly appreciate the data mining support of Matthew Halpern used in this study, and constructive comments from three anonymous reviewers.

\section{Research Support}

Cooperative Mobility for Competitive Megaregions University Transportation Center supported this study. 